\title{
Introduction to A Research Agenda for Heritage Planning: the state of heritage planning in Europe
}

Eva Stegmeijer, Loes Veldpaus and Joks Janssen

In this introduction we provide a framework for reading, explaining our intentions with the book, and our understandings of heritage planning. We will explain what the book addresses and aims for, and will also try to clarify what it does not do or include. The introduction has three sections. First, we introduce the emerging field and practice of heritage planning; second, we analyse the different positions of heritage in the planning system; third, we outline the three thematic challenges - identity, climate and development - that structure the various contributions to this book. We conclude this introduction by briefly recapitulating the main points this book addresses, and the agenda we want to raise for future research.

\section{Heritage planning: an emerging field of practice and research}

Recent decades have seen a mini revolution in the way we regard the vestiges of our past in the buildings and landscapes around us. In many countries, the preservation, conservation, management and development of the historic environment and of heritage assets have been increasingly integrated with spatial planning, making heritage more explicitly part of a dynamic system of future making. At the same time, heritage management has gradually changed and widened its scope, scale and ambition. Its operational repertoire has been enriched: from the protection of (single) historic monuments and sites, via the spatial development of larger areas and landscapes based on their historical structures, forms and uses, to providing meaning in all kinds of social, economic and spatial processes. 
Rather than just a material asset, heritage is now more commonly seen as a process of mobilizing some pasts for present-day purposes, and thus a future-making exercise (Hart 2011; Meskell 2015). As such, heritage can involve (a selection of) socio-cultural and socio-spatial arrangements - tangible and intangible, movable and immovable, natural and cultural resources - such as products, processes, patterns, perceptions, personal stories and memories, as well as the relations and values they constitute. This also means that conservation, as a process of caring for heritage, is about much more than preserving a small collection of listed buildings. A gradual transformation has taken place from a so-called 'culture of loss', in which limiting damage was the primary goal, towards 'a culture of profit' that creates designs for the future from a historically informed perspective (Janssen et al. 2017). Economic interests, cultural value and social vitality are now inextricably linked to contemporary notions of heritage planning.

\section{The heritage and planning nexus}

Today, revitalizing the historic environment is a common strategy in spatial transformation of European cities and countryside, and in territorial and socio-economic development schemes. There is a push for heritage policy to have an optimistic outlook in its approach to the material and immaterial remnants of the past. Rather than a constraint on spatial transformations, heritage is positioned as a driving force and source of inspiration for development. Across Europe and elsewhere, successful large-scale redevelopment projects, such as the Zeche Zollverein in Essen, the Amsterdam Westergasfabriek, the Aire River near Geneva and the New York High Line, have inspired policymakers, researchers and designers, as well as the public, to take a greater interest in, for example, the industrial or rural past. Rereading, reimagining and reusing the past as a valuable cultural resource for present-day and future purposes is part and parcel of the emerging field of heritage planning, understood as the application of heritage in local and regional planning (Kalman 2014; UNESCO 2011).

The domain where spatial planning and heritage management intersect is rather intriguing. This is where heritage is protected, conserved and transformed in - or sometimes in spite of - the context of plans, rules and regulations. It is where planning and place marketing meet. Planning is more and more focused on the existing city, infill and reuse; place branding often relies heavily on historic character, and heritage is often positioned as a unique selling point in commercially driven regeneration projects. Urban structures and uses are as much planning as they are heritage. Heritage brings old ideas as new perspectives and opportunities for planning, and vice versa. 
Accordingly, this book addresses the intersection of two different fields of research and practice that are, in themselves, highly diverse and interdisciplinary. On the one hand, spatial planning - and its wide variety of planning systems that are deeply embedded in local and national socio-economic, political and cultural contexts (Dühr et al. 2010), as well as ways of knowing and doing (Davoudi 2015) - builds on understandings created in social science perspectives as well as technocratic and design practices. On the other hand, heritage is virtually boundless, as it includes work on traditions and customs, museums and collections, buildings and urban structures, ruins and archaeology, cultural and natural landscapes, oral and public history, memory and identity, and more (Labadi and Logan 2015; Meskell 2015). It incorporates critical and practical perspectives, and has very different disciplinary roots, with work growing out of engineering and the natural sciences as well as the humanities and social sciences. Bringing these together, the book focuses on those instances and situations where heritage is actively positioned in spatial dynamics, and where planning for the future is about mobilizing structures, ideas and practices from the past. As heritage planning is a cultural activity, a policy field and an area of research, the book provides a mosaic of themes, approaches and recent developments in heritage planning research and practice.

\section{Structure, aim and scope of the book}

This research agenda on heritage planning addresses the new heritage frontiers in spatial planning, as well as the interrelated planning and policy challenges. What will these challenges mean for heritage planning practice, for planners, for heritage organizations and professionals in the years to come? What do they mean for scholars in the fields of heritage and planning? Throughout this book, the perspective is twofold. How can heritage be understood and dealt with within and through planning practices? And how can heritage planning contribute to spatial and social transitions, to identity and belonging, and to a (more) sustainable future? Various authors respond to the ongoing changes and reflect on the future of heritage planning reality and research.

The book has three parts. Part I sets the scene, Part II presents current research and Part III develops an agenda for future research. For Parts I and III, we have invited external reflections in the form of writings, reviews and interviews, while in the middle part, ten research teams from across Europe present their 
research projects, which were funded ${ }^{1}$ by the Joint Programming Initiative on Cultural Heritage and Global Change (JPI-CH $)^{2}$ in collaboration with the European Commission. These projects showcase the state of the art of heritage planning research in Europe. Not only have the recently finished projects shared their most topical results and outcomes; based on their experience, the authors (we invited project leaders to co-author with an early career researcher) also touch upon needs for future research. Rather than highlighting research we consider the most important or innovative, this compilation reflects the contemporary research landscape. It showcases international studies that currently receive (research) funding. Instead of narrowing down this myriad of approaches into one global agenda, our aim is to bring them together in one volume; to facilitate and stimulate further thinking in the field, be it through confrontation, contestation or collaboration.

The aim of this book is not only to present current research at the nexus of heritage and planning but to question its directions; and by doing so, to explore new and alternative futures for heritage planning in view of the pressing global challenges we are facing today, which demand collaboration, critical thinking and radical action. With this work, we position emerging trends based on empirical evidence, and pinpoint knowledge gaps. Our agenda is a mix of demand-driven research priorities, thought experiments and theoretical challenges. The book aims to be informative for those who study, perform, regulate and fund heritage planning research and practice, providing an accessible introduction to diverse heritage planning research themes, to new and emerging practices, concepts and criticisms. As such, this edition fits well with the series of Research Agendas this book is part of.

Although the field of heritage planning is a global one, the work in this book mainly focuses on a European context. It features research undertaken on the European Union (EU) level, as well as in Belgium, France, Italy, the Netherlands, Norway, Poland, Spain, Serbia, Sweden and the UK. The approaches identified across the continent are highly varied and it is safe to

1 A selection of interdisciplinary research projects granted in the Heritage Plus call, running between 2015 and 2018, funded by 14 countries partaking in the Joint Programming Initiative on Cultural Heritage and Global Change, and the European Commission under Grant agreement no. 618104, http://jpi-ch.eu/joint -activities/joint-call/ (accessed 29 July 2020).

2 JPI-CH is a network of European countries programming and funding transnational heritage research. It particularly stimulates studies that are responsive to policy and practice needs. The JPI-CH programme and this book are independent projects, but the mutual involvement of researchers, practitioners and funders means they have developed iteratively and interactively. 
say that a universal 'European' Heritage Planning does not exist. While, in general, the Eurocentric nature of heritage planning has increasingly been recognized (Graham et al. 2000; Meskell 2018), that approach in fact appears more specifically to have been developed in a particular subset of European countries, and mostly in urban contexts. This bias is reflected in the origin of the funded research projects and hence contributors to this book. One of the main agenda points is that we need to push beyond this Eurocentric approach, questioning the research it produces and the foundations on which it is developed, and providing funding for the projects and people who do this. We trust that the reader will be aware that their institutional and cultural settings may be extremely different from the ones described in this book, as are the varied interpretations of histories and heritage planning in different disciplinary contexts. Bringing them together can be as uncomfortable as it is critical, but it is needed in order to develop new openings and perspectives.

Throughout the remainder of this introduction, we will position heritage planning in conceptual terms. We will then illustrate and frame the rich variety of contributions that follow in the second part of this book through three major challenges we identify: heritage and identity, heritage and climate and heritage and development.

\section{Shifting approaches to heritage in planning}

In the planning of cities and regions, much of the focus has shifted from expansion and sprawl to redevelopment and regeneration. Over the last few decades, public and private actors and investors have started to change their conceptions of heritage in this context: less of a costly burden that impedes development opportunities, and more of a unique quality and strategic commodity to be used in revitalization and regeneration schemes. The economic value of heritage has been put on the agenda, considering and criticizing its role in fostering socio-economic development (Madgin 2020; Rypkema 2006; Veldpaus and Pendlebury 2019). The resulting conservation planning assemblage, with its many actors and agents and its approach to heritage as an economic asset in spatial dynamics, is now common in many planning situations across Europe and elsewhere (Pendlebury et al. 2019).

From the late twentieth century onward, with the sustainable development debate gaining momentum, more value has been placed on the use and development of environmental resources, of which heritage is seen as part and parcel. National and international heritage organizations have called for devel- 
opment to be attuned to and compatible with the historic environment, as well as the cultural traditions and values of communities (EU 2019; e.g. UNESCO 2011; UN-HABITAT 2016). The conservation of cultural resources has thus become entangled with emerging environmental and engagement agendas, placing new demands on heritage and planning. This shows that the planning context in which heritage conservation operates is constantly changing, as is the application of heritage in local and regional planning situations. As a result, both heritage and heritage professionals (and academics) must continuously demonstrate their value to society, as heritage competes for political support and scarce financial resources within complex local and regional agendas. The planning system seems the best available platform to do so and to connect with agendas in, for instance, housing, climate and participation. Within a planning context, heritage can most easily find its necessary allies to team up with. By doing so it can improve its scope, impact and efficacy. This can, however, also lead to the further erasure of certain parts of history, in order to 'better' serve certain economic, ecological or societal goals.

These new agendas have led to an increased emphasis on negotiation and collaboration, which also reflects and incorporates some of the criticisms that became more prominent with the rise of critical heritage studies, questioning a single, expert-led heritage discourse. This argues for a conceptualization of heritage that is fluid - heritage as a process - and produced within a much wider and more inclusive societal debate (Harrison 2013; Smith 2006). Communities of interest - local people, users, residents and tourists, for instance - are no longer considered only as heritage consumers, but as producers. This also means that multiple perspectives will be present in the continuous production of heritage, and those can be contested, conflicting, competing, convenient or complementary. This is increasingly reflected in the context of specific heritage sites, museums or events that are exploring what it means, for example, to work in a participatory manner, and to platform different perspectives and voices. Thus, the heritage debate is calling for more inclusive, diverse, dynamic and value-driven heritage approaches. The literatures and shared practices exploring how this plays out in the complexity of a planning context, and thus in public space, are, however, much less abundant.

\section{Heritage as sector, factor and vector}

From the moment heritage conservation first secured a foothold in the planning system, it has seen a further integration of its activity within the dynamic planning process. Although the level to which that has become part of legal structures and institutional practices varies across European nations, cities and regions, it is stimulated by intergovernmental organizations such as UNESCO 
(2011, 2016). In some countries, protection and planning are still very much separate legal systems, while in others, heritage conservation activity has formally been incorporated into spatial planning procedures and laws (Veldpaus et al. 2019). In line with the level of integration, the aims and expectations about what heritage can do, how this is to be achieved and by whom, are diverging. Several authors have analysed these divergent planning treatments of heritage as a dynamic and evolutionary (instead of revolutionary) process; they observe a shift from isolated preservation to integrated conservation and, finally, a broader notion of heritage planning (Ashworth 2011; Bosma 2010; Veldpaus 2015).

Another effort to characterize and visualize this process is the conceptual framework developed by Janssen et al. (2017), based on the development of the heritage planning nexus in the Netherlands. It sees three different approaches to dealing with heritage in planning: heritage as sector, as factor and as vector (Figure 1.1). While this model looks at different relations that have developed over time, it also shows that the different ways in which the fields of heritage and planning relate to each other do not phase each other out, but rather exist in various combinations. Janssen et al. frame the evolution of heritage in planning not as a paradigmatic revolution of different interrelationships, but rather as an evolutionary process in which new approaches build on previous ones. Thus, they acknowledge the delay between the introduction of new ideas on heritage and their adoption in planning frameworks, regulations and practice. Even though the mindset of academics is surely, and almost inevitably, infused by changing ideas on heritage, in daily reality practitioners obviously have to work within the boundaries of the policies and regulations in place. Thus, while new conceptualizations of heritage embody a real transformative potential, planning practice tends to advance step by step (Pendlebury 2009).

Heritage as sector refers to the idea that heritage is considered under threat by spatial and economic dynamics and should be preserved in designated areas in order to prevent loss. The idea of a sector also refers to heritage conservation being a separate system that has its own legal basis and is largely government-driven, and thus supportive of a national narrative in the context of the process of nation state formation (or creation).

With the changing conceptualization and shifting role of heritage from the 1980s onward, it became apparent that this preservationist approach could only be applied to a selection of the most important monuments and sites. In other cases, heritage became seen as an important factor in planning and regeneration strategies. In such instances, it is a negotiable aspect in market-driven spatial developments and public-private partnerships. Depending on the 
situation, adaptive reuse and/or radical alteration are just as viable options as preservation or conservation. In this heritage-as-factor approach, heritage experts as custodians need to negotiate with developers, investors, politicians and spatial planners.

Since the turn of the millennium, the growing importance of the 'intangible', as well as the value of the multiplicity of stories and meanings associated with buildings, districts and landscapes, has meant that heritage is seen as something that can inspire developments both in physical and non-physical terms. It is this multiplicity, and its recognition in spatial plans, that leads to the production of cultural value. Accordingly, heritage can function as a vector for spatial planning projects, providing an endless supply of historical sources and contexts that can guide development. Rather than relying on the government or the market, an active dialogue is sought with civic society. Subsequently, participatory approaches are important to decipher the stories and memories of local inhabitants. A wide range of stakeholders, and explicitly also the various local communities, are included in order to deliberately tie in with societal agendas, and to platform more voices, as a way to further develop and transform heritage for societal benefit.
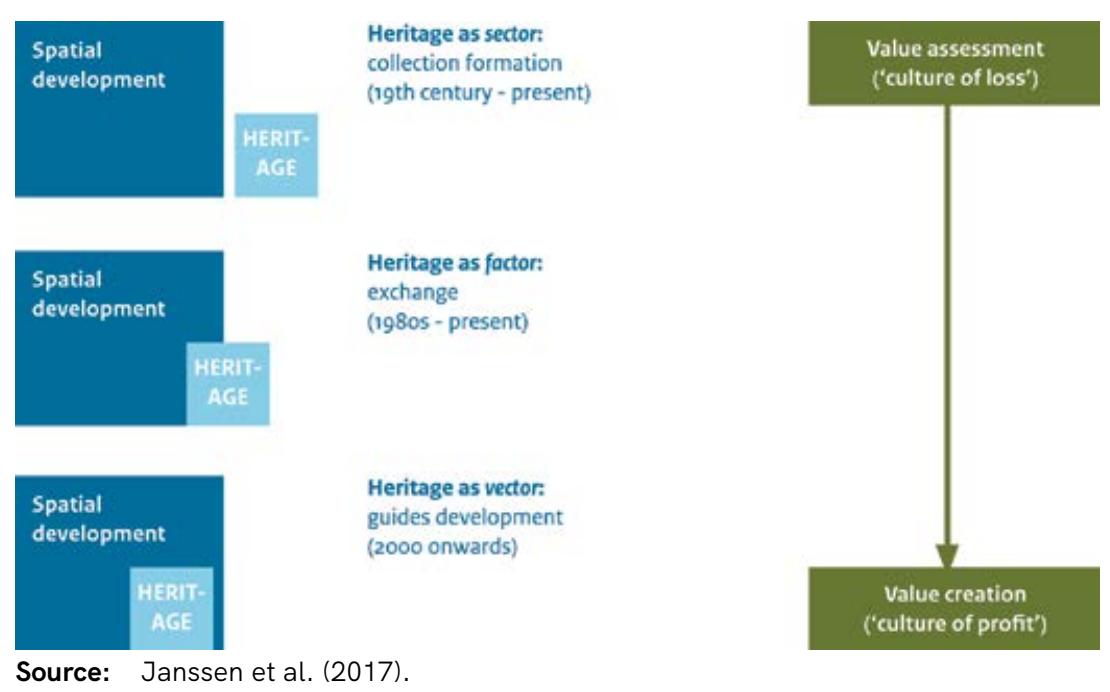

Figure 1.1

Conceptualization of the evolution of the interaction between heritage management and spatial planning 


\section{Layering of heritage approaches}

The enrichment of approaches and gradual integration of heritage into planning is mirrored in international guidelines for heritage conservation, as developed by UNESCO, ICOMOS or the Council of Europe (Veldpaus 2015; Veldpaus and Pereira Roders 2014). Whereas the Venice Charter of 1964 saw heritage as a separate domain and focused on individual sites and buildings, the 1975 Declaration of Amsterdam, further developed in the 1987 Washington Charter, positioned heritage conservation as part of spatial planning. With documents such as the 2003 Convention on Intangible Heritage and the 2005 Faro Convention, we see the push towards more participatory and inclusive approaches, taking stock of the (intangible) traditions and values of a community. These conventions acknowledge that planning and conservation cannot be separated from the cultural beliefs and values of a society, which must be safeguarded. The same holds true for the recommendation on Historic Urban Landscapes (UNESCO 2011), which promotes partnerships, participatory approaches and integration of heritage into socio-economic, cultural and environmental development.

The different approaches to heritage in spatial planning have certainly not precipitated any radical shifts between coordination mechanisms. Instead, they have brought about the expansion of the repertoire of heritage management in a planning context. The heritage as sector, factor and vector approaches each have their own raison d'être in current planning reality and study. Or, to put it differently, heritage management now has at its disposal a number of mechanisms and logical frameworks for dealing with the past, which in planning practice exist in parallel and in combination and are mutually dependent. Tensions between approaches are likely - unavoidable even - and there is a need for ongoing challenging of existing attitudes, as well as the development of new approaches. Contemporary heritage planning practice does not call for a uniform mode that can be applied to all heritage issues. Rather, the complexity of present-day heritage planning requires different modes of dealing with heritage in spatial plans and projects, and indeed flexibility to navigate between those.

As heritage becomes more integrated into spatial dynamics, it is also much more explicitly expected to facilitate and stimulate economic development (Veldpaus and Pendlebury 2019). This has various implications. It can more easily erase or abuse the results of participatory processes and ignore perspectives and voices that are not acting in the 'preferred' way. In other words, it makes even more likely processes of othering and exclusion, of un-belonging, and of being written out of history (Hall 1999). Moreover, consequences of 
the process of instrumentalizing heritage, such as gentrification and commodification, are regularly de-problematized and even celebrated (Beeksma and Cesari 2018). Heritage is supposed to achieve goals. This is also reflected in the so-called affective turn in heritage studies (Crooke and Maguire 2018; Smith et al. 2018), where a body of work is developing around the workings of heritage: what heritage does (Craggs et al. 2016; e.g. Davidson 2012; Kisić 2017; Sinclair-Chapman 2018; Tolia-Kelly et al. 2017). Consequently, we argue that an emerging approach can be identified, beyond sector, factor and vector: heritage as an actor. We will elaborate this in the final chapter of this book.

Today's heritage challenges require heritage and planning professionals to realistically assess the potentials as well as the doings of a historic building, site or landscape in view of its broader societal context, and to apply different approaches accordingly. Given the dynamic nature of how the built environment is valued, heritage planning is a constantly changing reality that is guiding as well as adding value to and through urban and rural transformation. It is our joint responsibility to reflect on common realities and policy frameworks, and make this an ethical and inclusive process, rather than an extractive and exploitative one. Actively using heritage to address structural societal problems like racism, climate change, uneven development and lack of diversity is a collective concern. It may reveal needs for radical changes to policies and practices, and an approach which acknowledges that heritage is not neutral: it is a process of selection and of reproducing and mobilizing certain values and histories, often at the expense of other values and histories.

\section{Challenges for heritage planning: identity, climate and development}

There are a number of changing 'environments' with a substantial impact on heritage planning in Europe, as identified by JPI Cultural Heritage (2020): changing physical, social and economic, and political and cultural environments. Urgent pressures on a global scale such as climate breakdown, increasing inequalities, uneven development, polarization and racism cannot be separated from heritage or planning. They challenge the status quo and require near-future solutions, as well as more long-term conceptual thinking and systemic change. Is heritage planning part of the solution, or part of the problem? As a broad and multifaceted field, there surely is no single answer to this, but it is a question we need to consider in our studies and our daily experiences. 
This book contributes to such reflection. We highlight the overarching themes of identity, climate change and (sustainable) development as perspectives in framing the current understandings of these societal challenges in relation to heritage planning. Depending on one's outlook on what heritage can offer, the responses to these challenges will be highly diverse, as Višnja Kisić (Chapter 2) underlines in her contribution. She provides an overview of the wider academic debates this book is part of while reflecting on the position of the presented research, exploring common themes as well as pinpointing omissions and implicit assumptions. Providing a practical perspective, Koenraad Van Balen and Aziliz Vandesande (Chapter 3) present their research on how heritage counts for Europe, linking heritage management with key societal challenges. Both contributions further develop the foundations for the remainder of the book, which is organized along these thematic strands of identity, climate and development. Our aim with these strands is to give an idea of the research done, as much as the research still needed.

\section{Heritage planning and identity}

Identity is one of the leading themes in heritage, as identity building is one of the main 'things' heritage is supposed to 'do'. That takes many forms, ranging from nation state building to place branding and ways to enable a sense of belonging. A recognition of the political and strategic nature of heritage is growing, but the workings of it are often not considered in full. Moreover, they are being negotiated in a conservation planning assemblage where other logics (for instance, economics or safety) have agency too (Pendlebury 2013).

Responding to this, new paradigms have arisen that focus on identity and inclusivity, by foregrounding decolonial, non-canonical, democratic and participatory heritage practices (JPI-CH 2020). How can we be more perceptive about perspectives, identities and histories in society that are often conveniently forgotten in conservation narratives? How do we deal with heritage that doesn't fit or suit our identity, doesn't tell our side of the story, doesn't acknowledge our existence? For some, these are questions to be negotiated daily; for others, they might be unknown issues and new questions. So, this thematic strand is about unpicking how heritage relates to identity; how people identify (or not!) with places, pasts and practices; and how this is made possible (or not) by the heritage planning frameworks in place.

In the section on identity (Part II, Section A), much attention is paid to the role of 'normal people' (e.g. laypeople, local communities) and other stakeholders in participatory heritage practices, while critically reflecting on how 'local identity' is selectively employed in regeneration strategies at 
a regional level and how heritage is part of identity politics at a European level. A thought-provoking introduction to the theme by Remi Wacogne (Chapter 4) is followed by Moore and Tully (Chapter 5) on oppida. These late Iron Age (un)enclosed settlements are in themselves a rather pure form of protected archaeological heritage. The structures are, however, also part of a wider landscape and a landscape management scheme that also needs to work for agricultural use, wildlife and hikers. How can the different understandings of this landscape play a role in an integrated landscape-based approach to heritage planning, and how can the different understandings support and enrich each other? Veldpaus and Wacogne (Chapter 6) focus on industrial heritage, critically assessing how the past is mobilized in the present. Sensitive to the downsides of the economic paradigm, and the nature of power relations and accountability, they assess how different groups of stakeholders and their narratives are positioned in such redevelopment schemes, particularly paying attention to the selectiveness by which stories from the past are put forward (or left out). The section continues with a contribution from Micoli et al. (Chapter 7). In case studies of archaeological heritage defined and managed by professionals, notions of civic engagement and local pride are explored through the use of new 3D technologies to the enhancement of (local) belonging and sense of place. Finally, Fiorentini et al. (Chapter 8) reveal the rather limited definitions of heritage that are used within European legal institutions. Since access to heritage is considered a basic human right, and European institutions employ heritage for identity politics, it is argued that a much more plural and diverse legal heritage perspective is needed, including minority and newcomers' perspectives.

\section{Heritage planning and climate}

Another key issue to be addressed on a global scale, and therefore also in the context of heritage planning, is climate change. Over the past two decades, this major societal challenge has entered heritage planning agendas. The impacts of global warming on the development of land, (cultural) landscapes, populations and their heritage are immense, interrelated and manifold. Research often focuses on monitoring and prevention of material loss. Much wider and deeper impacts on humanity, psychology and society are occurring in the disruption to how communities live and interact with their landscapes, and thus pasts and cultures. These profound changes are much less researched.

The predicted physical, but also cultural and social, impacts on heritage in its various forms are hard to comprehend. The Paris Agreement and the Habitat III New Urban Agenda stress the need for urgent and drastic changes to the patterns of production, consumption and living. The transitions to low-carbon, 
climate-resilient and sustainable pathways need to be ethical and fair. Impacts are not only directly caused by the effects of climate change, such as sea-level rise, but also by the measures taken to promote climate adaptation. New demands are placed on the landscape as a result of, for example, water safety measures, sustainable transport and large-scale renewable energy production and distribution sites. These will have an incredible impact on our cultural landscapes, but they are potentially also the cultural landscapes of the future.

Although it is important to mitigate and monitor negative impacts, there is a need to shift our thinking. Can we move from climate being 'a threat to heritage' to heritage being part of the solution to climate change? For example, through the (re)use of existing buildings, materials and 'embodied energy', and by learning from traditional practices, experiences and knowledges? In short, this thematic strand evaluates and discusses research on opportunities for mitigating and reversing negative impacts on heritage, as well as possible ways by which heritage structures and values can serve as inspirations for designing and planning post-fossil and climate-robust resilient environments.

In the section on climate (Part II, Section B), state-of-the-art technology is applied to assess risks and monitor degradation of UNESCO World Heritage Sites and inform mitigation and adaptation strategies. In Chapter 9, Margottini introduces this vast, dynamic and diverse field of study by quantitatively assessing the numbers of scientific publications devoted to research on heritage, climate and the interaction between them. Current research on the impact of climate change on heritage sites is then described by Spizzichino and Margottini in Chapter 11 and by De Angeli and Battistin in Chapter 12. Both chapters focus on listed heritage, analysing these risks in order to come up with the best ways to mitigate or prevent damage and loss of heritage.

On the other hand, in Chapter 10, Vallerani and Visentin explore the intangible heritage of waterways, looking at the meanings that past interventions, like canals, and natural phenomena, such as minor rivers, have for society. They touch upon how these currently underused or vacant water structures can be better used, both for increasing understandings of landscape and climate change and for practical applications like irrigation and outlets for peak supplies. Traditional, cultural and historical knowledge is essential to unravel the logic of old water systems and thus clearly identify bottlenecks and opportunities for climate adaptation. Heritage thus embodies a source of historical solutions that can be used (again) in today's plans and design schemes.

All in all, this section shows that heritage and climate influence each other. Besides needing to be protected from negative impacts, heritage can also have 
a transformative potential for the benefit of society. Heritage can help to raise awareness of the impacts of climate change on society, and vice versa.

\section{Heritage planning and development}

Complex transitions - such as climate change and the realization of inclusive and just societies - demand new perspectives in (and on) heritage planning and its role in urban and rural development. Particularly in the last two decades, approaches that integrate heritage and planning goals have been recommended, spurring the further incorporation of heritage into spatial development logics. This new role for heritage needs further understanding. Looking inwards is no longer an option: economic, political and social crises further increase the need for taking responsibility and position. Austerity measures following the financial crisis that erupted in 2008 also hit heritage management. In some instances, this halted large-scale demolition in favour of a more organic, small-scale transformation of the existing city and its environment, often driven by not-for-profit or community efforts. Towards 2020, however, the calls for new development (including housing) have been rising, while the consequences of a new economic crisis following the COVID-19 pandemic have yet to become clear. Though again hitting cultural institutions incredibly hard, such crises may also offer opportunities, for example, of more localized, socially just and sustainable development. Maybe, the capitalist logic of ongoing growth, and interlocal and interregional competition rather than collaboration, can be challenged this way? We however also need to ask questions like: what is the role of heritage in gentrification processes? How can issues like commodification and economic lock-in (such as the vulnerability of sole dependency on (international) visitors during the COVID-19 pandemic) be countered? How can heritage contribute to sustainable development in poor, peripheral or rural areas? The question of intangible heritage also comes in, as events, practices, activities, uses and traditions are just as much part of development as are assets and structures. How can this local 'DNA' be a template for future development and a means to enhance a sense of belonging and prevent out-migration, while also attracting in-migration, boosting quality of place and small-scale economic activity? In short, this thematic strand focuses on heritage as a potentially valuable asset for planning and development, but also shows the need to further understand the role of heritage in the context of place stewardship.

The section on development (Part II, Section C) therefore assesses the potential of heritage for regional development strategies, in terms of gastronomy and local produce, music festivals and maintenance works that are boosting skills and employment. In Chapter 13, Sjölander-Lindqvist introduces the playing 
field of heritage and development, pointing out the diverse value frameworks and conceptualizations of heritage which should be recognized in order to achieve social sustainability. In line with this, Chapter 14 by Whyton and Perry focus on how and by whom jazz music is considered as heritage, and what this means in terms of its spatial settings. Festivals, as (in)formally recognized heritage locations, are positioned as arenas for exchange on what is considered heritage, and whose narratives dominate and make the city, while promoting attention for undervalued or overlooked values and groups. Della Torre and Moioli (Chapter 15) analyse international cases of methods of (preventive) maintenance and integrated conservation of listed heritage, which at the same time promote societal and economic benefits such as the creation of jobs, promotion of training and skills, and community involvement. Finally, in Chapter 16, Sjölander-Lindqvist et al. focus on gastronomy and local produce, preparation and places for food exchange, such as markets, as heritage. Their contemporary value is explored in terms of (economic) development, regional branding and the creation of productive linkages between local producers.

The varied chapters in this section subsequently reflect how heritage in all its forms is positioned rather centrally in current (economic) development strategies for cities and regions. The aim is to positively impact on society, while also considering the balance between use and exploitation, and addressing inclusiveness in terms of which and whose heritage is considered.

\section{To conclude: new crossovers in heritage planning}

The different contributions to this book underline the variety in approaches to and perspectives on heritage planning: from fixed to fluid or gasiform, from preservationist to dynamic or developmental, from expert-led and top-down to community-driven and bottom-up, from the institutional to the personal, and from what heritage is (or seems to be) to what heritage actually does. In other words, the major societal transformations and spatial challenges can be approached both as threats and as opportunities for heritage; both forms (or a combination) are valid, depending on the issue at stake and the different stakeholders involved. Moreover, we see clear added value in a form of heritage planning in which these different approaches supplement and enrich each other. This also holds true for the new heritage frontiers in spatial planning, pushed forward by urgent issues of identity, climate and development. This results in different outlooks on heritage management and conservation. By bringing these outlooks together in one volume, we aim to bridge often sep- 
arate academic debates, inspire constructive heritage planning practices and innovative research projects and agendas, and stimulate public debate.

Stimulating crossovers in research on heritage planning is important. A multidimensional perspective could provide impetus for critical crossover research. Much can be gained by enabling more profound and lasting productive interactions within and between practice and research. We will elaborate on this more deeply in the final chapter of this book, when we propose an agenda for the future. In that agenda, we encourage wider, broadly engaged perspectives on heritage planning that contribute to addressing societal challenges. We explore comprehensive and creative ways of knowing and doing within and across the three pivotal themes. Heritage planning has transformative potential. We aim to encourage both practice and research directions to be aware of this potential, and position heritage planning within diverse movements for making our world more just, diverse and sustainable. By exploring challenging research questions, we hope to inspire new pathways and imaginings of doing and studying heritage planning in the future.

\section{References}

Ashworth, G. (2011), 'Preservation, conservation and heritage: approaches to the past in the present through the built environment', Asian Anthropology, 10 (1), 1-18.

Beeksma, A. and C.D. Cesari (2018), 'Participatory heritage in a gentrifying neighbourhood: Amsterdam's Van Eesteren Museum as affective space of negotiations', International Journal of Heritage Studies, 25 (9), 974-91.

Bosma, K. (2010), 'Heritage policy in spatial planning', in T. Bloemers, H. Kars and A.V. der Valk (eds), The Cultural Landscape and Heritage Paradox: Protection and Development of the Dutch Archaeological-Historical Landscape and its European Dimension, Amsterdam: Amsterdam University Press, pp. 641-51.

Craggs, R., H. Geoghegan and H. Neate (2016), 'Managing enthusiasm: between "extremist" volunteers and "rational" professional practices in architectural conservation', Geoforum, 74, 1-8.

Crooke, E. and T. Maguire (2018), Heritage after Conflict: Northern Ireland, Abingdon, Oxon; New York: Routledge.

Davidson, T. (2012), Stone Bodies in the City: Unmapping Monuments, Memory and Belonging in Ottawa, PhD Thesis, Edmonton, Alberta: University of Alberta.

Davoudi, S. (2015), 'Planning as practice of knowing', Planning Theory, 14 (3), 316-31.

Dühr, S., C. Colomb and V. Nadin (2010), European Spatial Planning and Territorial Cooperation, Abingdon, Oxon; New York: Routledge.

EU (2019), 'Urban Agenda for the EU', Text, accessed 26 May 2020 at https://ec.europa .eu/futurium/en/urban-agenda.

Graham, B., G. Ashworth and J. Tunbridge (2000), A Geography of Heritage: Power, Culture, and Economy, London; New York: Arnold; Oxford University Press. 
Hall, S. (1999), 'Whose heritage? Un-settling "the heritage", re-imagining the Postnation', Third Text, 13 (49), 3-13, doi: 10.1080/09528829908576818.

Harrison, R. (2013), Heritage: Critical Approaches, Abingdon, Oxon; New York: Routledge.

Hart, S. (2011), 'Heritage, neighborhoods and cosmopolitan sensibilities: poly-communal archaeology in Deerfield, Massachusetts', Present Pasts, 3 (1), https://doi.org/10.5334/pp.42.

Janssen, J., E. Luiten, H. Renes and E. Stegmeijer (2017), 'Heritage as sector, factor and vector: conceptualizing the shifting relationship between heritage management and spatial planning', European Planning Studies, 25 (9), 1654-72.

JPI Cultural Heritage (2020), Strategic Research and Innovation Agenda 2020, Joint Programming Initiative on Cultural Heritage and Global Change (JPI CH), accessed 10 May 2021 at https://www.heritageresearch-hub.eu/app/uploads/2020/12/SRIA -2020-1.pdf

Kalman, H. (2014), Heritage Planning: Principles and Process, Abingdon, Oxon; New York: Routledge.

Kisić, V. (2017), Governing Heritage Dissonance: Promises and Realities of Selected Cultural Policies, Belgrade: European Cultural Foundation (ECF).

Labadi, S. and W. Logan (2015), Urban Heritage, Development and Sustainability: International Frameworks, National and Local Governance, Abingdon, Oxon; New York: Routledge.

Madgin, R. (2020), 'Urban heritage and urban development', in S. Haumann, M. Knoll and D. Mares (eds), Concepts of Urban-Environmental History, transcript, Verlag.

Meskell, L. (2015), 'Introduction: globalizing heritage', in L. Meskell (ed.), Global Heritage: A Reader, Chichester: John Wiley \& Sons.

Meskell, L. (2018), A Future in Ruins: UNESCO, World Heritage, and the Dream of Peace, Oxford; New York: Oxford University Press.

Pendlebury, J. (2009), Conservation in the Age of Consensus, Abingdon, Oxon; New York: Routledge.

Pendlebury, J. (2013), 'Conservation values, the authorised heritage discourse and the conservation-planning assemblage', International Journal of Heritage Studies, 19 (7), 709-27.

Pendlebury, J., M. Scott, L. Veldpaus, W. van der Toorn Vrijthoff and D. Redmond (2019), 'After the crash: the conservation-planning assemblage in an era of austerity', European Planning Studies, 28 (4), 672-90, doi: 10.1080/09654313.2019.1629395.

Rypkema, D. (2006), 'Economics, sustainability, and historic preservation', Forum J, 20, 27-38.

Sinclair-Chapman, V. (2018), '(De)Constructing symbols: Charlottesville, the confederate flag, and a case for disrupting symbolic meaning', Politics, Groups, and Identities, 6 (2), 316-23.

Smith, L. (2006), Uses of Heritage, Abingdon, Oxon; New York: Taylor and Francis.

Smith, L., M. Wetherell and G. Campbell (2018), Emotion, Affective Practices, and the Past in the Present, Abingdon, Oxon; New York: Routledge.

Tolia-Kelly, D.P., E. Waterton and S. Watson (eds) (2017), Heritage, Affect and Emotion: Politics, Practices and Infrastructures, London; New York: Routledge, Taylor \& Francis Group.

UNESCO (2011), Recommendation on the Historic Urban Landscape, Paris: UNESCO World Heritage Centre, accessed 25 January 2018 at http://whc.unesco.org/uploads/ activities/documents/activity-638-98.pdf. 
UNESCO (2016), Culture: Urban Future: Global Report on Culture for Sustainable Urban Development, Paris: UNESCO.

UN-HABITAT (2016), 'The New Urban Agenda', accessed 26 May 2020 at http:// habitat3.org/the-new-urban-agenda/.

Veldpaus, L. (2015), Historic Urban Landscapes: Framing the Integration of Urban and Heritage Planning in Multilevel Governance, PhD Thesis, Eindhoven, Netherlands: Technische Universiteit Eindhoven, accessed 11 February 2016 at http://repository .tue.nl/798291.

Veldpaus, L. and J. Pendlebury (2019), 'Heritage as a vehicle for development: The case of Bigg Market, Newcastle upon Tyne', Planning Practice \& Research, $10.1080 / 02697459.2019 .1637168$.

Veldpaus, L. and A. Pereira Roders (2014), 'Learning from a legacy: Venice to Valletta', Change over Time, 4 (2), 10.1353/cot.2014.0022.

Veldpaus, L., F. Fava and D. Brodowicz (2019), Mapping of Current Heritage Re-use Policies and Regulations in Europe Complex Policy Overview of Adaptive Heritage Re-use, OpenHeritage: Deliverable 1.2, Newcastle upon Tyne, England, December, p. 254. 